DOI: https://doi.org/10.24867/13BE23Boskovic

\title{
SERVIS ZA IZRADU PODLOGE ZA AKADEMSKO PRIZNAVANJE PERIODA MOBILNOSTI
}

\section{SERVICE FOR CREATING A BASIS FOR ACADEMIC RECOGNITION OF MOBILITY PERIODS}

\author{
Vuk Bošković, Fakultet tehničkih nauka, Novi Sad
}

\section{Oblast - ELEKTROTEHNIKA I RAČUNARSTVO}

Kratak sadržaj-Ovaj rad opisuje proces implementacije sistema za olakšavanje procesa izrade dokumenta za priznavanje perioda mobilnosti, kao i stvari koje su prethodile implementaciji.

Ključne reči: Studentska mobilnost, poslovni procesi, veb servisi.

\begin{abstract}
This paper describes the process of implementing a system to facilitate the process of drafting a document for recognizing mobility periods, as well as things that preceded implementation.
\end{abstract}

Keywords: Student mobility, business processes, web services.

\section{UVOD}

Kontekst vremena u kojem živimo, jasno nam govori da ljudi imaju sve veću želju za putovanjima i upoznavanjem novih kultura. Ova potreba, naročito se izražava kod mladih ljudi, a studenti, kao većina ove grupe, često imaju problem da pronađu vremena i sredstva kako bi je zadovoljili.

Jedan od najboljih načina da se ovo reši jeste odlazak na studentsku mobilnost. Studentska mobilnost se može realizovati na više načina: studentskom razmenom, stručnom praksom u inostranstvu, studijama na više univerziteta i druge. Razmene, kao najčešći oblik mobilnosti sve su popularnije među studentima koji žele da probaju život $u$ inostranstvu i sve je više programa preko kojih se mogu realizovati. Ovi programi, često pružaju finansijsku pomoć studentima, kako bi razmene bile pristupačne za sve i kako materijalna sredstva ne bi predstavljala prepreku za odlazak na razmenu.

Problem vremena koje će biti utrošeno na odlazak na mobilnost, odnosno problem produktivnosti na razmeni i stručnoj praksi rešava se različito, na različitim fakultetima. Fakultet tehničkih nauka, Univerziteta u Novom Sadu ovo pitanje rešava sastavljanjem Podloge za akademsko priznavanje perioda mobilnosti.

Ovaj dokument sadrži osnovne podatke o studentu koji ide na razmenu, osnov mobilnosti, u kom periodu će se mobilnost odviti i na kojoj instituciji. Ukoliko se radi o studentskoj razmeni, podloga sadrži dve tabele sa informacijama o ispitima koje će student slušati na

\section{NAPOMENA:}

Ovaj rad proistekao je iz master rada čiji mentor je bio dr Milan Segedinac, vanr. prof. razmeni. Prva tabela sadrži ispite koji, ukoliko budu položeni, biće uvaženi za isti ili sličan predmet sa fakulteta sa kog student ide na razmenu. Da bi se predmet našao u ovoj tabeli potrebna je saglasnost predmetnog profesora sa matičnog fakulteta. Druga tabela sadrži one ispite koji će, ukoliko budu položeni, biti priznati na matičnom fakultetu kao dodatak diplomi. Popunjena podloga mora biti potpisana od strane šefa studijskog programa na kojem je student. Šef pregleda popunjenu podlogu i ukoliko ona zadovoljava sve uslove potpisuje je, kako bi podloga bila važeća po povratku studenta sa razmene.

Proces pravljenja dokumenta za priznavanje, traženja saglasnosti profesora, traženja potpisa šefa studijskog programa zahteva dosta vremena. Potrebno je da svaki pojedinac izdvoji dodatno vreme kako bi učestvovao u ovom procesu. Cilj ovog rada je olakšavanje procesa za izradu podloge, gde bi se učesnici procesa povezali preko mrežnog servisa, postavljenog kao poslovni proces koji na kraju sam generiše podlogu u PDF formatu i pruža mogućnost preuzimanja za potpis

\section{TEORIJSKE OSNOVE}

Studentske razmene, kao najčešći oblik studentske mobilnosti, mogu se realizovati preko više programa razmene. Univerziteti i fakulteti putem programa razmene stvaraju međusobnu saradnju. Ovim putem, studentima jednog univerziteta ili fakulteta je omogućeno da se prijave na konkurs za razmenu na instituciji sa kojom je ostvarena saradnja. Osim same mogućnosti da deo studija provede na stranoj instituciji, program razmene studentu često nudi i finansijsku podršku, odnosno određenu stipendiju tokom trajanja razmene, kako finansije ne bi predstavljale prepreku u odluci studenta da se prijavi na neki od aktivnih konkursa. Ovo je posebno bitno za studente iz zemalja koje nisu ekonomski razvijene i znatno povećava broj zainteresovanih za razmene.

Proces prijave na konkurs za studentsku razmenu predstavlja složen proces $\mathrm{i}$ još jednu prepreku u prijavljivanju na konkurs. Da bi se student prijavio na konkurs, potrebno je da sakupi svu neophodnu dokumentaciju i usmena odobrenja aktera procesa. Takođe, želja studenta je da, pored upoznavanja kulture i sticanja novih poznanstava, razmenu provede efikasno i sa akademske strane, odnosno da predmeti koje bude položio na stranoj instituciji budu priznati kao zamena za neke od predmeta na instituciji sa koje ide na razmenu. Ovo bi značilo da je potrebna neka vrsta garancije za 
studenta da će njegov trud i položeni predmeti na razmeni biti vrednovani kad se razmena završi. Rešenje ovog problema Fakultet tehničkih nauka, Univerziteta u Novom $\mathrm{Sadu}$, pronalazi u potpisivanju posebnog dokumenta pre početka razmene.

\section{SPECIFIKACIJA ZAHTEVA}

Ovo poglavlje će se baviti specifikacijom zahteva koje je potrebno ispuniti kako bi sistem bio što efikasniji.

\subsection{Prikupljanje zahteva}

Za svaki inženjerski problem, čije rešenje predstavlja neki softverski proizvod, neophodno je da se na početku rešavanja, jasno definišu zahtevi koje bi taj proizvod trebalo da ispunjava.

Kako bi se zahtevi definisali, potrebno je da se pribegne nekom od načina prikupljanja zahteva. Autor ovog rada izabrao je intervjuisanje za metodu prikupljanja zahteva. Ovo je najčešća metoda prikupljanja zahteva i podrazumeva anketiranje korisnika sistema za koji se softver pravi.

\subsection{Definisanje poslovnog procesa}

Sve prikupljene informacije su obrađene u cilju što boljeg shvatanja izvršavanja procesa. Iz svih informacija se jasno može videti da je ceo proces vrlo složen, sa posebnim naglaskom na proces izrade Podloge.

Proces za izradu ovog dokumenta uključuje više učesnika, odnosno više tipova učesnika koji imaju različite zadatke ili aktivnosti koje izvršavaju u okviru procesa. Svi ovi zadaci su međusobno koordinisani i vode do jednog zajedničkog cilja - izrade

Podloge za akademsko priznavanje perioda mobilnosti. Pošto proces sadrži sve navedene karakteristike, zaključeno je da može biti posmatran kao poslovni proces [2].

\subsection{Slučajevi korišćenja}

Za dobro razumevanje problema izrade Podloge za akademsko priznavanje perioda mobilnosti definisani su slučajevi korišćenja kroz tabelarni prikaz. Svaki slučaj je detaljno prikazan u tabeli, kroz opis, učesnike, uslove koje je potrebno ispuniti pre, kao i posledicama korišćenja.

\section{IMPLEMENTACIJA}

U ovom poglavlju biće omogućen pregled implementacije ranije definisanog sistema i procesi koji su joj prethodili, kao što su modeliranje poslovnog procesa implementiranog sistema i modelovanje podataka.

\subsection{Poslovni proces i modelovanje podataka}

$\mathrm{S}$ obzirom na prirodu procesa izrade podloge za akademsko priznavanje, ranije tokom ovog rada zaključeno je da će se gledati kao poslovni proces. Kao takav, imaće najveći uticaj na funkcionisanje sistema. Znajući ove činjenice, pre implementacije je definisan precizan model poslovnog procesa kojim će se serverska aplikacija voditi, a upravljanje njime Camunda framework omogućiti [10]. Model poslovnog procesa za funkcionisanje se može videti na slici 4.1 .

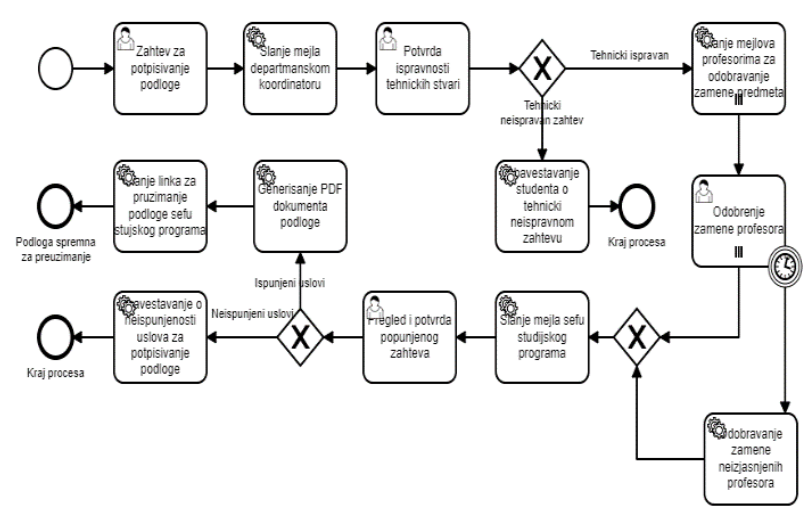

Slika 4.1. Model poslovnog procesa sistema

Još jedna stvar koja prethodi implementaciji je modelovanje podataka. Neophodno je napraviti dobar model podataka kako bi baza podataka mogla efikasno da ih skladišti i time poboljša performanse sistema.

\subsection{Implementacija funkcionalnih zahteva}

Prvi zahtev koji je bilo potrebno ispuniti je omogućavanje studentu da podnese novi zahtev za izradu Podloge za akademsko priznavanje perioda mobilnosti. U svakom momentu, na svakoj stranici, pri vrhu prozora prisutan je navigacioni bar čija je uloga da omogući pristup raznim aktivnostima koje je moguće sprovoditi. Nakon pristupa aplikaciji, klikom na obeleženu komponentu navigacionog bara „Podnesi zahtev“, korisnik odlazi na stranicu na kojoj mu je ponuđen formular za prijavu. Formular je potrebno prvo popuniti osnovnim podacima o studentu kao što su: ime, prezime, broj indeksa, smer i osnovne informacije o periodu koji će provesti razmeni. Deo formulara u koji se tiče osnovnih informacija se može videti na slici 4.2 .

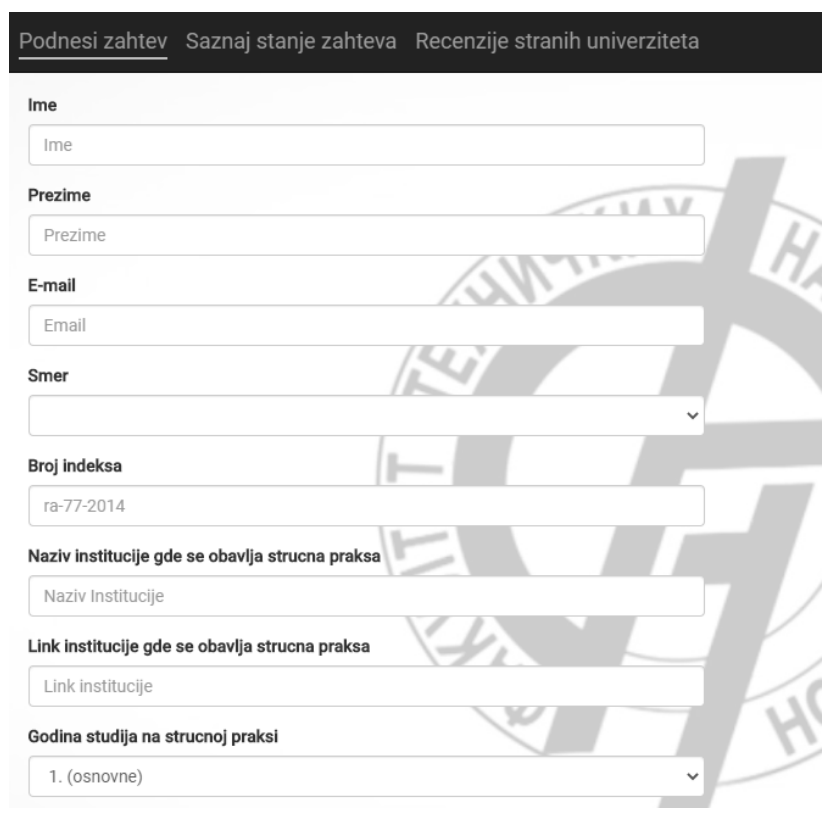

Slika 4.2. Deo formulara za podnošenje zahteva

Drugi deo formulara tiče se predmeta koji će biti slušani na stranoj instituciji. S tim ciljem, korisniku je ponuđeno da u drugi deo forme ubaci podatke o predmetu koji će slušati i da odabere opciju da li taj predmet ima zamenu na njegovom fakultetu.. 
Nakon uspešno podnetog zahteva studenta, izvršava se prvi zadatak u modelu poslovnog procesa, a nakon njega se automatski izvršava servisni zadatak - „Slanje mejla departmasnkom koordinatoru“ i aktivira sledeći korisnički zadatak „Potvrda tehničke ispravnosti zahteva“" koji se dodeljuje departmanskom koordinatoru. Isti svom zadatku pristupa putem linka dobijenog elektronskom poštom, sa objašnjenjem šta je potrebno da uradi kao učesnik procesa. Link u sebi, pored putanje do stranice sadrži i jedan parametar. Vrednost tog parametra predstavlja ID instance poslovnog procesa i omogućava pregled tačno određenog podnetog zahteva. Nakon pregleda, departmanski koordinator donosi odluku o tehničkoj ispravnosti. Ukoliko je odluka da zahtev nije tehnički ispravan, izvršiće se automatski servisni zadatak koji studentu šalje mejl sa obaveštenjem o tome i komentarom ukoliko ga je koordinator ostavio, a izvršavanje procesa će se prekinuti. Sa druge strane, ukoliko je odluka potvrdna, nastaviće se sa izvršavanjem i pokrenuće se servisni zadatak za slanje mejla profesorima čiji su predmeti predloženi za zamenu.

Profesori moraju imati mogućnost da potvrde da li se slažu sa zamenom njihovog predmeta, nekim drugim predmetom sa strane institucije. Ovaj zahtev im je ispunjen veoma prostim rešenjem. Nakon potvrdne odluke koordinatora, svi profesori dobijaju mejl koji sadrži objašnjenje o tome šta je predlog studenta, svim podacima o tome i koji je njihov zadatak u celom procesu. Izvršavanje tog zadatka podrazumeva donošenje odluke o slaganju sa zamenom njihovog predmeta i rešava se klikom na jedan od dva linka iz mejla. Odlaskom na prvi link, profesor se izjašnjava potvrdno sa zamenom predmeta, a klikom na drugi odrično. Izgled strukture jednog ovakvog mejla može se pogledati na slici 4.3.

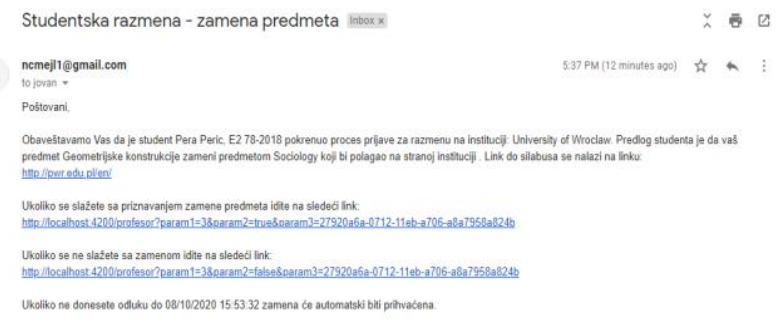

Slika 4.3. Primer mejla za profesora

Znajući da su profesori često zauzeti i da zbog obimnosti posla, puno studenata ili drugih obaveza, nekad nemaju vremena da donose ovakve odluke u kratkom vremenskom intervalu, bilo je potrebno vremenski ograničiti izvršavanje njihovog zadatka. Ovaj zahtev se rešio dodavanjem tzv. Boundary timer event-a na zadatak profesora. Time je omogućeno vremensko ograničenje, koje, ukoliko se ne ispoštuje, preusmerava izvršavanje procesa na alternativni tok izvršavanja. Model poslovnog procesa sada preusmerava tok na servis koji automatski prihvata zamene predmeta svih profesora koji se nisu izjasnili do tada. Nakon ovog zadatka, alernativni tok se vraća prvobitnom toku, zamišljenom u slučaju da se svi profesori na vreme izjasne.

Skoro isto kao departmanskom koordinatoru, šefu studijskog programa je omogućeno da izvrši svoj zadatak. Nakon dobijenog mejla u kojem je obavešten da su profesori doneli odluku i linka sa parametrima koji ih vodi do stranice za izvršavanje zadatka, pregledaju zahtev i ispunjenost uslova. Zatim donose odluku i ostavljaju komentar ukoliko smatraju da ima potrebe za tim. Ukoliko je odluka negativna, studentu se šalje mejl sa razlogom odbijanja njegovog zahteva za izradu podloge, sa komentarom ili savetom šefa, ukoliko ga je ostavio. Sa druge strane, ukoliko je odluka pozitivna, proces pokreće servisni zadatak za izradu PDF dokumenta. Za implementaciju servisa je korišćena biblioteka iText PDF koja omogućava rad sa PDF dokumentima. Primer jedne ovako izgenerisane podloge može se pogledati na slici 4.4 .

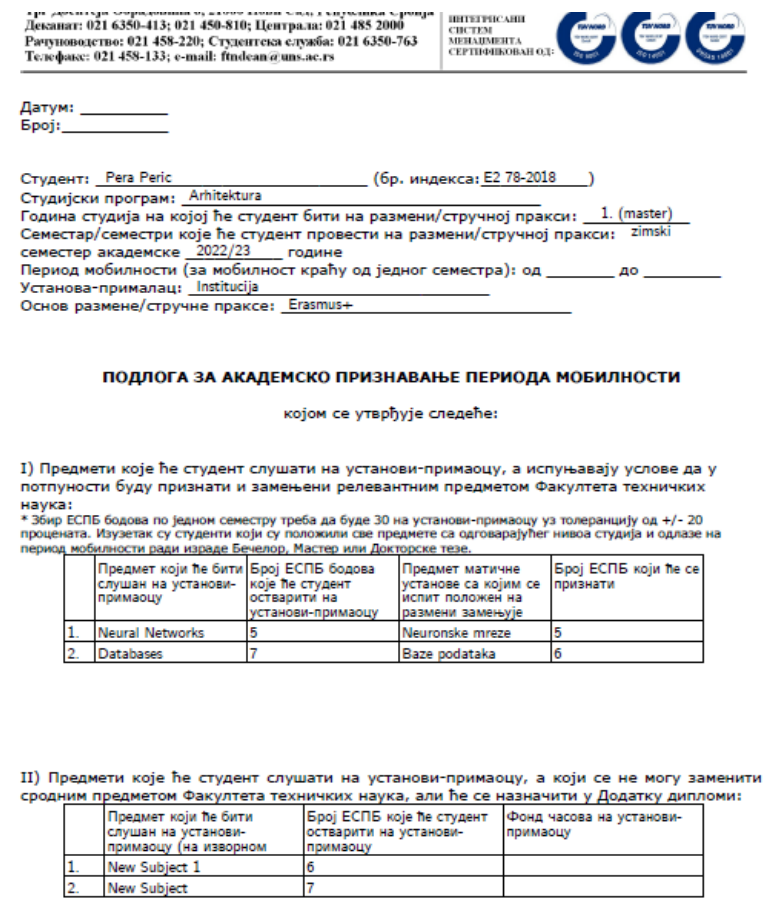

Slika 4.4. Primer izgenerisane podloge

Nakon servisa za generisanje podloge, shodno toku procesa, izvršava se i servis za slanje elektronske pošte. Šefu studijskog programa se šalje mejl sa linkom na kom može izvršiti preuzimanje podloge. Za dobavljanje PDF fajla sa serverske aplikacije i omogućavanje njegovog preuzimanja sa klijentske aplikacije korišćena je biblioteka Filesaver.

\subsection{Implementacija nefunkcionalnih zahteva}

Problem motivacije studenta za odlazak na razmenu i odabir univerziteta, odnosno lokacije na kojoj će sprovesti razmenu, može se rešiti na više načina. Postoje različiti pristupi za rešavanje ovog problema. Pristup koji je korišćen u ovom radu je izrada sistema za ocenjivanje perioda provedenog na razmeni.

Ovo podrazumeva pružanje studentu mogućnost da u svakom momentu može da pogleda recenzije univerziteta, lokacija i iskustava drugih studenata, koji su tamo ranije sproveli svoju razmenu. Slika 4.5. sadrži prikaz slučaja korišćenja funkcionalnosti izrađene sa ciljem rešavanja ovog problema. 


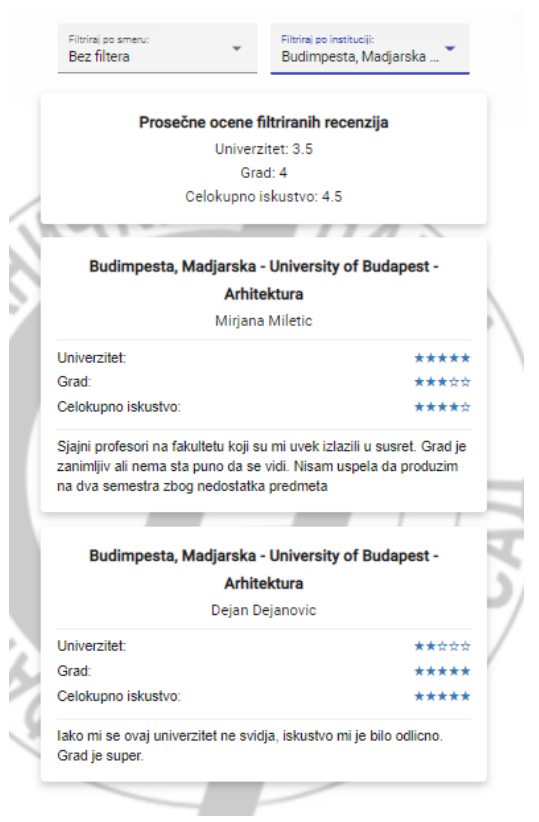

Slika 4.5. Primer korišćenja servisa za pregled recenzija

Da bi se recenzije mogle prikazivati, potrebno je da budu unete $\mathrm{u}$ bazu podataka. $\mathrm{S}$ toga je dodata još jedna funkcionalnost u sistem - dodavanje recenzije. Kako bi se implementirala ova funkcionalnost, u bazu podataka su uneti test podaci o studentima koji su bili na razmeni. Nakon završene razmene, studentima se šalje generički mejl sa molbom da napišu recenziju svog perioda provedenog na razmeni i tako pomognu ostalim studentima da steknu neku okvirnu sliku o njima. Uz molbu, u poruci se nalazi i link, na kom student može obaviti zadatak dodavanja recenzije. Link u sebi sadrži parametar čija vrednost predstavlja identifikacioni broj tog studenta pod kojim se čuva u bazi podataka. Na osnovu ove vrednosti, sistem prepoznaje koji student je napisao recenziju.

\section{ZAKLJUČAK}

Inženjerski sistemi imaju za cilj olakšavanje posla njihovim korisnicima, a to je slučaj i sa sistemom opisanim u ovom radu. Cilj spajanja učesnika na brz način, ispunjen je u potpunosti. Učesnici ovog procesa mogu uz par klikova mišem da izvrše svoje zadatke, što govori o efikasnosti načina na koji je ovaj problem rešen. Camunda framework pokazao se kao dobar izbor za alat koji će upravljati poslovnim procesom i time se preporučio za druge radove koji rade sa poslovnim procesima. Sa druge strane, jasno je da ovaj sistem ima mnogo potencijala za proširenje u različitim pravcima. Prvo što se nameće kao moguće proširenje je dodatak koji bi se bavio poslovnim procesom cele prijave na konkurs za razmenu, a ne samo izradom Podloge.

Ovo rešenje bi moglo da pomogne pri prikupljanju dokumentacije, njenom organizovanju i olakša prikupljanje potpisa neophodnih za ostalu dokumentaciju. Još jedno potencijalno proširenje bi mogao predstavljati dodatak za prijavu stranih studenata koji bi aplicirali za dolazak na Fakultet tehničkih nauka. Ovim bi se i broj dolaznih studenata na Fakultet tehničkih nauka povećao kao i ukupan broj studenata koji odlaze na razmenu, što je jedan od ciljeva ovog rada.

\section{LITERATURA}

[1] Z. Gračak and L. Brkić, "Software supporting international student exchange program in Higher Education," 2017 40th International Convention on Information and Communication Technology, Electronics and Microelectronics (MIPRO), Opatija, 2017, pp. 1528-1533, doi: 10.23919/MIPRO.2017.7973664.

[2] Brumec, J., \& Brumec, S. (2011). Modeliranje poslovnih procesa. Varaždin: Koris.

[3] Bjelica, D. (2020). SISTEM ZA AUTOMATIZACIJU PROCESA IZDAVANJA LICENCI ZA FIZIČKOTEHNIČKO OBEZBEĐENJE. Zbornik radova Fakulteta tehničkih nauka u Novom Sadu, 35(04), 805-808.

[4] Suwarto, N. A. (2015). Student Exchange Program Web Based Application System (Outbound). IRC.

[5] Mustafar, S. N. (2015). INBOUND STUDENT EXCHANGE PROGRAM WEB-BASED SYSTEM. IRC.

[6] Pettersen, T. M., \& Andersen, L. L. (2017). Developing a Web Application and a Case-based Reasoning Recommender System to Improve Students' Motivation for Exchange Programs (Master's thesis, NTNU).

[7] Ramlan, M. I. I. (2014). UTP Exchange Student Program System (Outbound). IRC.

[8] MAZALAN, M. A. (2014). Web Based Application: An Online Management System for the Student Exchange Program in Universiti Teknologi PETRONAS. IRC.

[9] Dirks, R. (2010). The experiences of student exchange program participants: a phenomenological study.

[10] The Camunda BPM Manual. (2020). Preuzeto 5. avgusta 2020., sa https://docs.camunda.org/

[11] Rodriguez A., (2008). "RESTful Web services: The basics", IBM.

[12] Angular. Preuzeto 10. septembra 2020., sa https://angular.io/

[13] Bruegge B. \& Dutoit A. (2009). Object-Oriented Software Engineering Using UML, Patterns, and Java (3. izd.). Pearson.

[14] Ilić, J. (2020). APLIKACIJA ZA UPRAVLJANJE RAZMENOM STUDENATA PUTEM ERASMUS+ PROGRAMA. Zbornik radova Fakulteta tehničkih nauka u Novom Sadu, 35(03), 474-477.

[15] Portal mobilnosti studenata, (2020). Preuzeto 5. jula 2020., sa http://mobility.ftn.uns.ac.rs/

\section{Kratka biografija:}

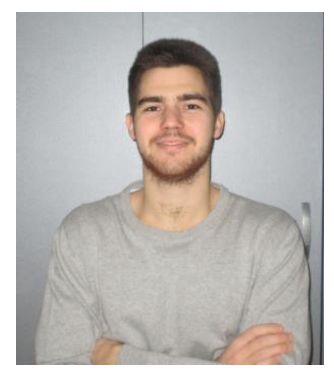

Vuk Bošković rođen je 1994. god. u Novom Sadu. Završio je gimnaziju „Laza Kostić“ u Novom Sadu 2013. godine. Fakultet tehničkih nauka je upisao iste godine. Odbranio je diplomski rad 2018. godine na temu „Programski jezik Kotlin“, nakon čega nastavlja sa master studijama na istom fakultetu.

kontakt: vukboskovic3@gmail.com 